Three unobtrusive domestic occupancy measurement technologies under qualitative review

Eldar Naghiyev $^{1 \mathrm{a}}$, Mark Gillott ${ }^{1 \mathrm{~b}}$, Robin Wilson ${ }^{1 \mathrm{c}}$

${ }^{1}$ University of Nottingham, University Park, Nottingham, NG7 2RD, UK

a laxen1@nottingham.ac.uk

${ }^{\mathrm{b}} \underline{\text { mark.gillott@ nottingham.ac.uk }}$

${ }^{\mathrm{c}}$ robin.wilson@ nottingham.ac.uk

Corresponding author: Eldar Naghiyev laxen1@ @ottingham.ac.uk +44 (0)7967513182

Abstract

Almost one third of the UK's total energy is consumed by the domestic sector. Occupancy measurement could have the potential to save significant amounts of that energy, either instantly via a home automation system or retrospectively via post-occupancy evaluation. However, not many localisation technologies are applicable to a domestic environment. In this paper three unobtrusive occupancy measuring technologies, i.e. Passive Infra-Red (PIR), Carbon Dioxide $\left(\mathrm{CO}_{2}\right)$ and Device-free Localisation (DfL), are compared. Their operation is explained and possible advantages and disadvantages are outlined. A qualitative experimental study then analyses the abilities of each system to detect overall occupancy, detect room level occupancy, count the number of occupants and localise them. It has been found that $\mathrm{CO}_{2}$ and PIR sensors are very limited. The impacts of other factors, such as windows or occupants' metabolic rates, were significant on the reliability of the measured data. Device-free localisation on the other hand has great potential, but requires further research.

Keywords: device-free; localisation; signal strength; CO2; passive infra-red; occupancy; occupant detection

1. Introduction 
The domestic sector consumed 30.5\% of the UK's final energy in 2010 [1]. Improving the energy efficiency of a dwelling is a challenge, as a variety of factors influence its energy consumption. One attempt has been to give occupants feedback of their energy consumption and thus make them consciously change their behaviour [2]. Providing occupants additionally with their location could further increase the potential of this method as shown in [3].

Other attempts have been made by using automation systems, as even the most energy aware consumer would not be able to control on a 24 hour basis, for example, complex heating patterns that are related to the outdoor weather changes and associated lags in fabric heat flows. Boait and Rylatt [4] demonstrated a space and water heating control system that based on occupancy data was able to achieve savings of approximately $14 \%$. Karjalainen et al. [5], who suggest the use of a spatially integrated control system, highlight that occupancy detection is crucial in order to improve energy efficiency, as their presence and level of activity needs to be known. However, if energy saving measures are taken autonomously, there could be conflicts of interest between the occupants and the automation system. To reduce or even prevent their occurrence the number of occupants and their locations should also be detected. Furthermore, this would allow the system to take more educated decisions; and similarly the resolution of information given through post-occupancy evaluation could be increased.

However, there are not many localisation systems that are appropriate for a domestic environment. Video surveillance for instance can be excluded for privacy reasons; the Global Positioning System (GPS) is not able to penetrate external walls and even other tag-based systems, such as Radio Frequency Identification (RFID), would restrict the occupants to wearing tags. In a domestic environment a localisation system is required, which does not reveal the occupant's identity, which is unobtrusive, which needs low maintenance, which is visually pleasing and which is energy efficient itself. Two established systems fulfilling these requirements have been identified. They are based on Carbon Dioxide $\left(\mathrm{CO}_{2}\right)$ and Passive Infra-Red (PIR) sensors. These as well as an emerging third technology called Device-free Localisation (DfL) will be introduced and analysed in this paper. In section 2 each system will be explained in detail, along with their advantages and disadvantages. Section 3 will describe the methodology used to experimentally compare the three technologies. The results will then be described in section 4. Finally, section 5 will discuss the findings, suggest further research areas and conclude the paper. 


\section{Technology descriptions}

\section{1. $\mathrm{CO}_{2}$ technology}

Humans naturally exhale $\mathrm{CO}_{2}$ on a constant basis. Therefore, the $\mathrm{CO}_{2}$ concentration in a building can be used as an indicator of occupancy, assuming humans are the only major source of $\mathrm{CO}_{2}$ in the building. Human's $\mathrm{CO}_{2}$ generation rate depends heavily on their metabolic rate, which itself depends on the type of activity they are doing. This is clearly shown in Levine et al.'s [6] table 1, which has been quoted by Leephakpreeda et al. [7].

However, the metabolic rate is dependent on other factors too and there is no proven method of measuring it in real time. Therefore, research projects assume that the changes in $\mathrm{CO}_{2}$ generation related to the metabolic rate are marginal and that an average value can be taken. Leephakpreeda et al. [7], as well as others [8-10], made this assumption in their experiment to deduce the number of occupants from the $\mathrm{CO}_{2}$ measurements.

The experiments took place in schools or office buildings. Some of these experiments were conducted by placing a $\mathrm{CO}_{2}$ sensor in a single room $[7,8]$. Although this is advantageous for demonstration purposes and experimental simplicity, not many buildings can be represented by a single room. In domestic buildings, interior doors are frequently used to separate spaces. Also, occupants, compared to pupils or office workers, are more likely to move around inside their house. The created air circulation patterns spread the $\mathrm{CO}_{2}$ content over a wider space. Consequently, $\mathrm{CO}_{2}$ content might be measured in unoccupied areas. References $[9,10]$ tried to bypass this complexity by simply measuring the $\mathrm{CO}_{2}$ content in the corresponding ventilation ducts. Although, occupancy can be detected, this method does not have the potential to localise a person.

Ventilation systems are the reason the $\mathrm{CO}_{2}$ based occupancy measurement was introduced. To meet indoor air quality standards, ventilation systems need to measure the level of pollution. $\mathrm{CO}_{2}$ is one of the most common gases in the atmosphere and therefore an ideal reference factor. Also, as mentioned, $\mathrm{CO}_{2}$ is exhaled by humans on a constant basis. Hence, the Demand Controlled Ventilation (DCV) strategy assumes that the number of persons present can be estimated using their average $\mathrm{CO}_{2}$ emission rates to then adapt the ventilation rate [11]. In this context the ventilation rates are controlled and known at all times. However, in domestic environments the ventilation rates can vary significantly, as ventilation is often achieved by opening windows instead. The relation between emitted and extracted $\mathrm{CO}_{2}$ content is therefore not linear anymore and makes it more difficult to estimate the number of persons present. 
Also, $\mathrm{CO}_{2}$ sensors have a significant reaction time. Meyn et al. [12] estimate it to be between 10 to 20 minutes. Emmerich and Persily [13] demonstrate that it is dependent on the volume of the room and the ventilation rate. However, this approach still assumes the air content to be well-mixed due to constant ventilation. In a nonventilated room many other factors could influence the reaction time, such as the $\mathrm{CO}_{2}$ dissipation within the room, the layout of the room, the infiltration rate, etc. In addition, real world variables, like wind speed and pressure differences, would have an impact. This delay in reaction time would be especially problematic if the residence time of occupants was short. Control strategies, which require fast switching times, could not be implemented. Even the efficiency of slower strategies would be affected.

\subsection{PIR technology}

Passive Infra-Red sensors exploit the fact that heated objects emit infra-red light. They detect moving objects of one temperature on a background of another temperature. In buildings the PIR sensors are usually adjusted as closely as possible to the average human body temperature to identify occupancy more effectively. However, heat currents from HVAC systems can also trigger a PIR sensor, as mentioned by Teixeira et al. [14]. This is called false positive output and can simply be sensor related as in Dodier et al.'s experiment [15]. PIR sensors also suffer from false negative outputs, for example if occupants remain still. Furthermore, Akhlaghinia et al. [16] demonstrated in a domestic-like environment that PIR sensors can have difficulties to cover the desired visual area. They also point out the case in which a sensor associated with one room, is triggered by events in another room.

Floyd et al. [17] showed that PIR controlled lighting, using a time-delay algorithm, can result in energy savings as well as energy wastage. They conclude that the setup, i.e. the sensors, their location and the associated control, is the key factor. In addition, Floyd et al. highlighted that occupancy patterns and ownership of space also impact potential energy savings.

The PIR sensor's output is binary and can therefore not differentiate between the presences of one or several persons. A misconception is that the rate of triggering can be used to infer the number of occupants. However, PIR sensors have the advantage that they are cheap, low in energy consumption, easy to deploy and that they operate in real-time. 


\subsection{DfL technology}

In recent years a new human presence measuring technology has been developed based on radio signals. Devicefree Localisation does not require the person to take actively part. It simply exploits the fact that the human body absorbs partially a radio signal, thus decreasing the received signal strength (RSS). Intensive research has been carried out with radios based on the IEEE 802.11 standard, also known as Wi-Fi. Seifeldin et al. [18], for example, located a static person in an area of $750 \mathrm{~m}^{2}$ with an average error of $6.74 \mathrm{~m}$. They suggest that DfL works particularly well at the $2.4 \mathrm{GHz}$ frequency, as this corresponds to the resonant frequency of a water molecule and as the human body is mainly made of water. The IEEE 802.11 standard is very data and power intensive and therefore its main application is the wireless connection to internet access points. However, it is not suited for home automation equipment. The IEEE 802.15.4 standard on the other hand, is more appropriate as it is designed for low data rates, low power and high reliability. Radios of this standard also operate in the unlicensed $2.4 \mathrm{GHz}$ frequency band and are therefore similarly sensitive to human presence. Wilson and Patwari [19] proved that successfully by tracking a person in an area of $72.5 \mathrm{~m}^{2}$ with an average error of $1 \mathrm{~m}$. They also showed that DfL works through walls.

At the moment, a difficulty for DfL is the reliable estimation of the number of people present. Nakatsuka et al. [20] suggest that it can be deduced from the average and the variance of the RSS. However, their results do not show a linear relationship with the number of people present. They also suggest that the link quality indicator (LQI) might give more information, as it takes the noise into account.

Besides noise multipath propagation impacts the quality of the signal. This phenomenon is mainly related to scattering and reflection of the signal within the environment [21]. Vance et al. [22] employed a filter to reduce these effects. Alternatively, the signal patterns in the environment can be learned previous to the localisation and can then be taken into account during. Kosba et al. [23] demonstrated such an approach successfully. However, the training required for such algorithm could prove problematic in a domestic environment. In a different study, Kosba et al. [24] demonstrated that the line-of-sight of the communicating radios is especially sensitive to human presence. The infrastructure should therefore carefully be designed to improve the localisation of occupants. 
The test-bed chosen to compare occupant detection strategies is a 3 bedroom domestic house. It is equipped with $\mathrm{CO}_{2}$ sensors on the landing and in every living area, i.e. the living room, the dining room and all bedrooms. The living areas as well as the kitchen are also fitted PIR sensors on the ceiling. In addition, several temperature and humidity (TH) sensors are fitted throughout the house. All the $\mathrm{CO}_{2}$, PIR and TH sensors have embedded Jennic JN5139 modules. Each module includes an IEEE 802.15.4 transceiver, which is operated by the JenNet protocol. The data recorded by the sensors is sent approximately every 4 minutes via routers to a data logging system. The system stores these values and simultaneously records the signal strength associated to each of the sensors. JenNet, unlike most, calls the signal strength LQI and not RSS. This could lead to confusion, as the term LQI is used in other literature for the distortion of the signal and not its strength. For consistency the term LQI will be used as replacement for RSS in this article. A signal "sniffer" has also been used to monitor the network traffic.

Additionally, the house is equipped with a tag based ultra-wideband (UWB) tracking system, called Ubisense. This will be used as a reference during the tests to measure the actual location of the participants. The layout of the $\mathrm{CO}_{2}$ and PIR sensors is illustrated in figure 1. The TH sensors as well as other components of the JenNet network are not represented, as the relation between their positions and the occupants' positions might not be linear. The UWB Ubisense sensors are also shown in figure 1.

Furthermore, the house is equipped with a MVHR. The air is extracted from the kitchen, the bathroom and the toilet. The fresh air is supplied to all living areas, i.e. living room, dining room, $1^{\text {st }}$ bedroom, $2^{\text {nd }}$ bedroom and $3^{\text {rd }}$ bedroom. The extraction and supply of the MVHR can be switched on/off independently. The DCV strategy described earlier, does not apply to this MVHR, it only operates at a constant extraction/supply rate?

The floor area of rooms positioned above each other, e.g. the living room and 1st bedroom, are approximately equal in floor area, as can be seen in Table 2. However, the room height is different between the ground and first floor and therefore is the volume of these rooms. In order to draw comparisons, overlaid rooms will be treated as equally sized.

Each of the three systems mentioned will be tested to determine whether it can detect occupancy, differentiate the number of people present and has the potential to localise an occupant within a room.

\section{Results}


The experiment took place over several days. The findings of the individual days were similar; therefore only one day's data will be presented in this paper.

The house was occupied between 10:45 and 18:00 by the three occupants A, B and C. Each of the occupants had been given a UWB tag with an individual identification number. In table 3 the actual location of the occupants during the experiment has been transcribed from the Ubisense recordings. In addition, circumstances that could affect $\mathrm{CO}_{2}$ or PIR results have been included.

\section{1. $\mathrm{CO}_{2}$ measurements}

The house was unoccupied between approximately 18:00 the previous day and the start of the experiment. The data from all the sensors are plotted in figure 2 to give an impression of their relative responses before discussing each in detail. The initial $\mathrm{CO}_{2}$ content measured by all sensors was between 400 and 500ppm. These values correspond to typical outdoor $\mathrm{CO}_{2}$ content and can therefore be taken as baseline reference. The $\mathrm{CO}_{2}$ concentration then starts to rise shortly after the occupants are present.

The person in each room was most of the time further than $0.6 \mathrm{~m}$ away from the $\mathrm{CO}_{2}$ sensors, as suggested by [11], in order to not directly influence the measurements. In the figures 3 to 7 the individual room's $\mathrm{CO}_{2}$ measurements are plotted against recorded occupancy.

In order to explore the effects of variable space separation, the interior doors have been closed from 12:00 to 13:00 and from 17:00 to 18:00 as shown in table 3. In the first case, it can be seen that before 12:00 the $\mathrm{CO}_{2}$ content increased in all areas of the house, even unoccupied once. Once the doors were closed, the content in the occupied rooms accumulated faster whilst it slightly decreased in the unoccupied rooms. Very important is also the moment when the doors were opened again. The air with the higher $\mathrm{CO}_{2}$ content mixed with the air of the unoccupied rooms. This could lead to misinterpretation of occupation or mask the actual change of location of an occupant, as happened in the experiment. As shown in table 3 occupant A, who occupied the living room, moved to the front bedroom when all doors were opened at 13:00. These results suggest that a $\mathrm{CO}_{2}$ sensor's output is highly dependent on the air circulation within its space.

Furthermore, $\mathrm{CO}_{2}$ measurements also dependent on air circulation between indoor and outdoor space. The $\mathrm{CO}_{2}$ level in the dining room, which has been occupied throughout the whole experiment, has been rising more slowly than in other rooms. The initial baseline level of the dining room $\mathrm{CO}_{2}$ sensor and its sharp drop at $6 \mathrm{pm}$ 
suggests that there might be higher localised air flows around the $\mathrm{CO}_{2}$ sensor. This could be due to a higher infiltration rate of the dining room, related to the finishing, or the position of the sensor which is, as shown in figure 1, relatively close to a French door. Both of these causes can only be revealed during the commissioning of a $\mathrm{CO}_{2}$ system and can therefore hardly be taken into account during the design stage.

Also, drafts are often voluntarily created either by ventilation systems or by occupants using windows. To assess the impact, both scenarios have been tested. The MVHR has been switched on from 15:00 to 16:00. The only room occupied was the dining room. Even though two persons were present at this time, the $\mathrm{CO}_{2}$ levels dropped for approximately 30 minutes before stabilising.

Once the MVHR was switched off again, the window in the living room has been opened from 16:00 to 17:00. Surprisingly, the $\mathrm{CO}_{2}$ level in the dining room dropped below the $\mathrm{CO}_{2}$ level in the living room, although both were occupied by one person during this period. This phenomenon could be explained with the suggested draft in the dining room. However, both, the MVHR test and the window test, highlight that $\mathrm{CO}_{2}$ occupancy detection is influenced by air quality improving measures. As mentioned in section 2, knowing the ventilation rate could improve the estimation of the $\mathrm{CO}_{2}$ emission rate. Nevertheless, it would comprise the accuracy of the $\mathrm{CO}_{2}$ system.

The ability of the $\mathrm{CO}_{2}$ system to detect the number of people has been examined. Two persons were present in the dining room between 14:20 and 16:00. In figure 4 the $\mathrm{CO}_{2}$ levels shown are distinctively higher during that period. It also needs to be reminded, that the MVHR, which has an outlet in the dining room, was switched on from 15:00 to 16:00. However, the $\mathrm{CO}_{2}$ level were similar to those of the living room and $2^{\text {nd }}$ bedroom during the period with closed doors when only a single person was present in each of those rooms. On the other hand, the very sharp rise in the living room between 17:00 and 17:30 is not related to an increased number of occupants, but only to the increased metabolic rate of a single occupant due to physical exercise as mentioned in table 3. Therefore, conclusions cannot be drawn reliably on the number of occupants based on $\mathrm{CO}_{2}$ content.

\subsection{PIR measurements}

The measurements represented in figure 8 are the times each PIR sensor has been triggered in the 4 minute time interval and are again presented on a single plot to compare the combined sensor data with the occupancy of the house. It shows that overall occupancy has been detected correctly. 
The presence has also consistently been detected within the single rooms, as shown in the figures 9 to 14 .

However, the PIR sensors were prone to negative false outputs. Several time intervals had no PIR measurements although the room was occupied. This occurred in all rooms and was probably caused by a reduced amount of movement of the occupant. The longest period of negative false measurement was in the living room for half an hour between 11:38 and 12:07.

Positive false outputs on the other hand have not been detected. The figures 11, 12 and 14 show values outside the occupied periods, however, they are all related to events that took place. In the kitchen, the bin has been used at several occasions and the opening and closing of its door has been measured. In the $1^{\text {st }}$ bedroom and $3^{\text {rd }}$ bedroom the closing of the doors at 12:00 and 17:00 respectively has been detected.

Furthermore, it has been noticed that the PIR sensor in the kitchen, shown in figure 11, has been triggered very often between 14:00 and 14:20. However, the person has consciously been very still in that time period. The higher output could be related to the fact that the person was standing, rather than sitting. Also, the kitchen has a significantly smaller surface area than the other rooms. Smaller stimuli could therefore trigger greater outputs. It could also simply be sensor related. The pure heating of the pan or the lighting up of the hob whilst cooking can be ruled out as a cause, because the same hot pan has been left on from 14:20 to 15:00, which did not trigger anything.

Also, having two people in the same room did not result in greater PIR peaks as can be seen in figure 10 . The average might be slightly higher over that period, but the average was also high around 11:00 when just a single person was present. The only real information that can be deducted from PIR values is the amount of movement that is taking place in the sensor's visual area. The assumption that greater movement equals more people present cannot always be applied. Over the whole day the biggest PIR values were measured in the living room between 17:00 and 17:30, which were caused by the physical activity of occupant A.

\subsection{DfL measurements}

The signal strength of all the PIR sensors, $\mathrm{CO}_{2}$ sensors, TH sensors and routers communicating via JenNet is shown in figure 15. This was examined to see if variations correlated with the presence of occupants. 
The signal strength for the occupied period from 10:45 to 18:00 has a clearly distinguishable pattern compared to the rest of the day. The fluctuations mainly before, but also after that period are related to the way the Jennic modules calculate their LQI value.

$\mathrm{LQI}=(47-\mathrm{MED}) * 6$

If $(\mathrm{LQI}<0) \mathrm{LQI}=0$

Else if $(\mathrm{LQI}>255) \mathrm{LQI}=255$

MED represents the number of gain stages required for the correct reception of a package and 47 is the maximum number of gain stages available.

Therefore, if the signal is slightly noisy and varying between 2 gain stages, the LQI value will vary in step sizes of 6. These variations also seem to occur periodically. During the occupied period on the other hand, the LQI values vary less symmetrically. Additionally, the variations are often greater to one step size of 6 and supported by other sensors with similar signal changes. Indeed, a significant peak of the Landing TH sensor is shown in figure 15 between 01:47 and 01:51. However, it occurred by itself with no support of other sensors and it took the value 255 , which seems very discontinuous.

Several sensors during the experiment changed from a medium LQI value abrupt to the maximum value of 255. Six sensors had the maximum LQI value of 255 over the entire 24 hour period. These sensors gave correct readings and worked fine, however it is believed that this particular value might have several functionalities. Besides representing the signal strength, it might also be used as replacement for missing signal strength information.

The signal "sniffer" showed that the connections were constantly rerouted. JenNet has a self-heal function, which finds new connection paths if the existing path is degrading. This function however makes it very difficult to know the real-time communication path and the associated line-of-sight. Therefore, it was not possible to associate a location or room to the signal strength of a specific radio, i.e. although a sensor is positioned in one room, the human presence in another room might impact its signal strength more. Also, it has been noticed that a lot of network traffic was navigated through the same connection paths. This decreases the area covered by radio signals and could lead to blind spots.

In figure 16 are the LQI values of two sensors represented, whose signal clearly responded to the combined human presence over the entire measurement period. It is noticeable that the signals started varying before the 
occupants entered the house and also after they left it. As radio waves travel through walls, DfL purely aimed at indoor applications could be prone to give feedback related to events that take place outside the desired area.

\section{Discussion and Conclusion}

Three unobtrusive occupancy measuring technologies that could be applied to domestic environments have been outlined. $\mathrm{CO}_{2}$, PIR and DfL technologies were assessed in an experimental setup, which found that all were able to detect overall occupancy of the dwelling. However, each technology had intrinsic restrictions.

In order to improve occupant localisation using $\mathrm{CO}_{2}$ sensors, the air circulation patterns in the environment need to be known and measured. Simulations backed-up by real data would be beneficial to assess the quality of the finishing of the building, i.e. the infiltration rates. In addition, doors and windows would need to be monitored. Also, data from existing ventilation system could be linked in and some form of predictive algorithm would be required to compensate for the slow response time of $\mathrm{CO}_{2}$ sensors.

The PIR system on the other hand can hardly be improved, as the negative false outputs are intrinsic to the sensors mode of operation. However, increasing the density of deployed sensors and varying the visual angles could improve their detection abilities. Advanced algorithm could potentially infer the number of occupants in specific setups.

Another option could be to combine several occupant detection systems, as described by Meyn et al. [12] and Dong et al. [25]. The gathered data could complement each other to deduce more information. However, $\mathrm{CO}_{2}$ and PIR are both prone, directly and indirectly, to the metabolic rate of occupants. Therefore, even combined they would have difficulties to determine the number of occupants. Also, occupants might be reluctant to install a great amount of sensors in their dwelling, as this increases costs and maintenance. Especially if the sole purpose of the sensors is to localise the occupants.

Device-free Localisation on the other hand has the advantage that it comes without any additional hardware costs, as most home automation systems are based on wireless radio connections. The exploitation of the data as well as the optimal setup would require further research work. The overall occupancy detection has already been successfully demonstrated. The research literature suggests that there is potential for DfL to detect the position and the number of occupants without the need for complimentary information. Also, events happening outside the dwelling could be monitored. 
References

[1] MACLEAY, I., HARRIS, K., ANNUT, A. and chapter authors (2011), "Digest of United Kingdom Energy Statistics (DUKES) 2011”, London

[2] DARBY, S. (2006), “The Effectiveness of Feedback on Energy Consumption: A Review for DEFRA of Literature on Metering, Billing and Direct Displays”, Environmental Change Institute, University of Oxford

[3] GILlOTT, M., HOLLAND, R., RIFFAT, S., FITCHETT, J.A. (2006), "Post-Occupancy Evaluation of Space Use in a Dwelling Using RFID Tracking”, Architectural Engineering and Design Management, Vol. 2, No. 4, pp. $273-288$

[4] BOAIT, P.J. and RYLATT, R.M. (2010), “A method for fully automatic operation of domestic heating”, Energy and Buildings, Vol. 42, pp. 11-16

[5] KARJALAINEN, S. and LAPPALAINEN, V. (2011), "Integrated control and user interfaces for a space", Building and Environment, Vol. 46, No. 4, pp. 938-944

[6] LEVINE, K.B., STERLING, E.M. and COLLETT, C.W. (1993), "Estimation of Outdoor Air Ventilation Rates Using CO2 Concentration”, ASHRAE Transactions, pp. 99(1)

[7] LEEPHAKPREEDA, T., THITIPATANAPONG, R., GRITTIYACHOT, T. and YUNGCHAREON, V. (2001), “Occupancy-Based Control of Indoor Air Ventilation: A Theoretical and Experimental Study”, ScienceAsia, Vol. 27, pp. 279-284

[8] LU, T., KNUUTILA, A., VILJANEN, M. and Lu, X. (2010), “A novel methodology for estimating space air change rates and occupant $\mathrm{CO}_{2}$ generation rates from measurements in mechanically-ventilated buildings", Building and Environment, Vol. 45, pp. 1161-1172

[9] WANG, S., BURNETT, J. and CHONG, H. (1999), “Experimental Validation of $\mathrm{CO}_{2}$-Based Occupancy Detection for Demand-Controlled Ventilation”, Indoor and Built Environment, Vol. 8, pp. 377-391

[10] ROULET, C.-A. and FORADINI, F. (2002), "Simple and Cheap Air Change Rate Measurement Using $\mathrm{CO}_{2}$ Concentration Decays”, International Journal of Ventilation, Vol. 1, No. 1, pp. 39-44 
[11] SCHELL, M. and INT-HOUT, D. (2001), "Demand Control Ventilation Using $\mathrm{CO}_{2}$ ", ASHRAE Journal, Vol. 43, No. 2, pp. 18-29

[12] MEYN, S., SURANA, A., LIN, Y., OGGIANU, S.M., NARAYANAN, S. and FREWEN, T.A. (2009), “A Sensor-Utility-Network Method for Estimation of Occupancy Distribution in Buildings", in Proceedings of $48^{\text {th }}$ IEEE Conference on Decision and Control, Shanghai, China, 15-18 December

[13] EMMERICH, S.J. and PERSILY, A.K. (2001), "State-of-the-Art Review of $\mathrm{CO}_{2}$ Demand Controlled Ventilation Technology and Application”, National Institute of Standards and Technology NISTIR 6729

[14] TEIXEIRA, T., DUBLON, G. and SAVVIDES, A. (2010), “A Survey of Human-Sensing: Methods for Detecting Presence, Count, Location, Track, and Identity”, ACM Computing Surveys

[15] DODIER, R.H., HENZE, G.P., TILLER, D.K. and GUO, X. (2006), "Building occupancy detection through sensor belief networks", Energy and Buildings, Vol. 38, pp. 1033-1043

[16] AKHLAGHINIA, M.J., LOTFI, A., LANGENSIEPEN, C. and SHERKAT, N. (2009), “Occupancy Monitoring in Intelligent Environment through Integrated Wireless Localization Agents”, in Proceedings of IEEE Symposium on Intelligent Agents, Nashville, USA, 30 March-2 April, pp. 70-76

[17] FLOYD, D.B., PARKER, D.S. and SHERWIN, J.R. (1996), "Measured Field Performance and Energy Savings of Occupancy Sensors: Three Case Studies", in Proceedings of ACEEE Summer Study on Energy Efficiency in Buildings, Pacific Grove, USA, 25-31 August

[18] SEIFELDIN, M. and YOUSSEF, M. (2010), “A Deterministic Large-Scale Device-Free Passive Localization System for Wireless Environments", Proceedings of $3^{\text {rd }}$ International Conference on PErvasive Technologies Related to Assistive Environments, Samos, Greece, 23-25 June, pp. 1-8

[19] WILSON, J. and PATWARI, N. (2009), “Through-Wall Motion Tracking Using Variance-Based Radio Tomography Networks", Technical Report

[20] NAKATSUKA, M., IWATANI, H. and KATTO, J. (2008), “A Study on Passive Crowd Density Estimation using Wireless Sensors", Proceedings of the $4^{\text {th }}$ International Conference on Mobile Computing and Ubiquitous Networking, 11-13 June

[21] PATWARI, N. and WILSON, J. (2009), "People-Sensing Spatial Characteristic of RF Sensor Networks", ARXIV, arXiv:0911.1972 
[22] VANCE, P., PRASAD, G., HARKIN, J. and CURRAN, K. (2010), “Analysis of Device-free Localisation (DFL) Techniques for Indoor Environments", Proceedings of IET Irish Signals and Systems Conference, Ireland, Cork, 23-24 June, pp. 76-81

[23] KOSBA, A.E., SAEED, A. and YOUSSEF, M. (2011), "RASID: A Robust WLAN Device-free Passive Motion Detection System”, ARXIV, arXiv:1105.6084

[24] KOSBA, A.E., ABDELKADER, A. and YOUSSEF, M. (2009), "Analysis of a Device-free Passive Tracking System in Typical Wireless Environments”, Proceedings of $3^{\text {rd }}$ International Conference on New Technologies, Mobility and Security, Egypt, Cairo, 20-23 December, pp. 1-5

[25] DONG, B., ANDREWS, B., LAM, K.P., HÖYNCK, M., ZHANG, R., CHIOU, Y.-S. and BENITEZ, D. (2010), “An information technology enabled sustainability test-bed (ITEST) for occupant detection through an environmental sensing network”, Energy and Buildings, Vol. 42, pp. 1038-1046

Figures
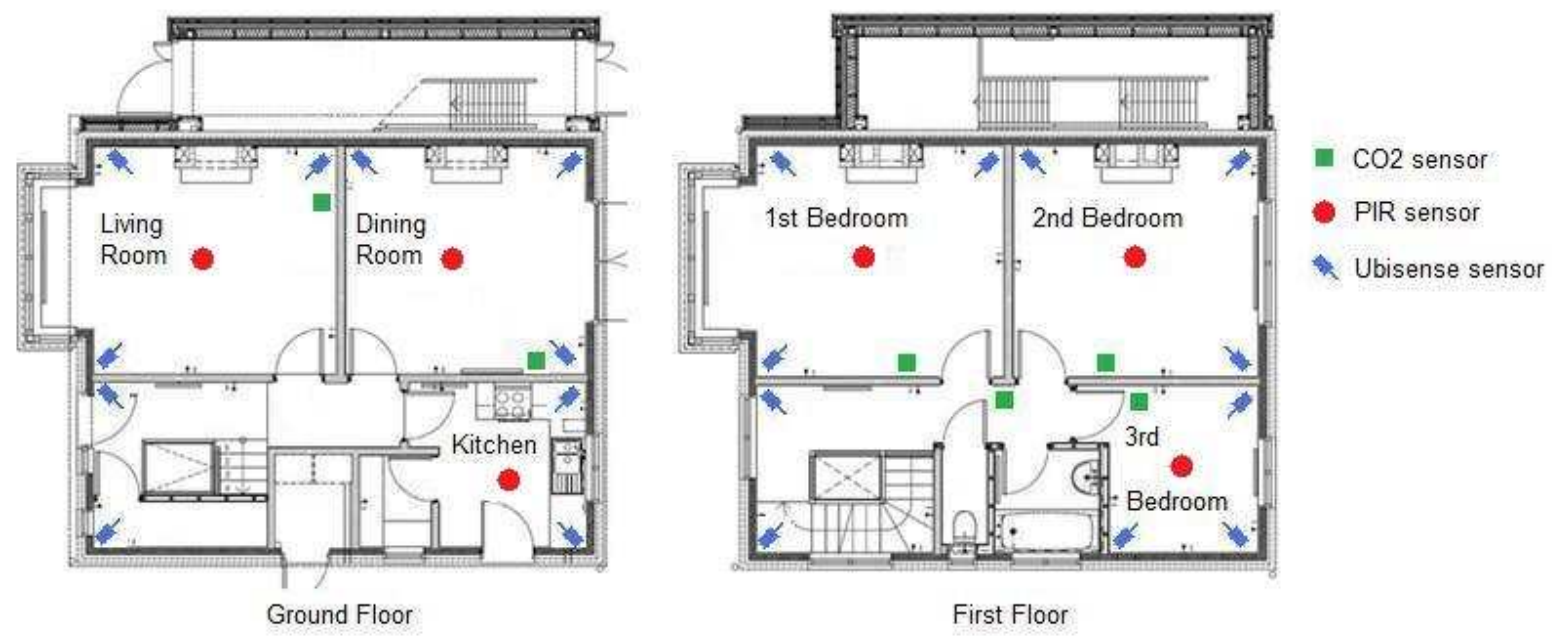

Figure 1: Floor plans of the house with $\mathrm{CO}_{2}$, PIR and Ubisense sensors 


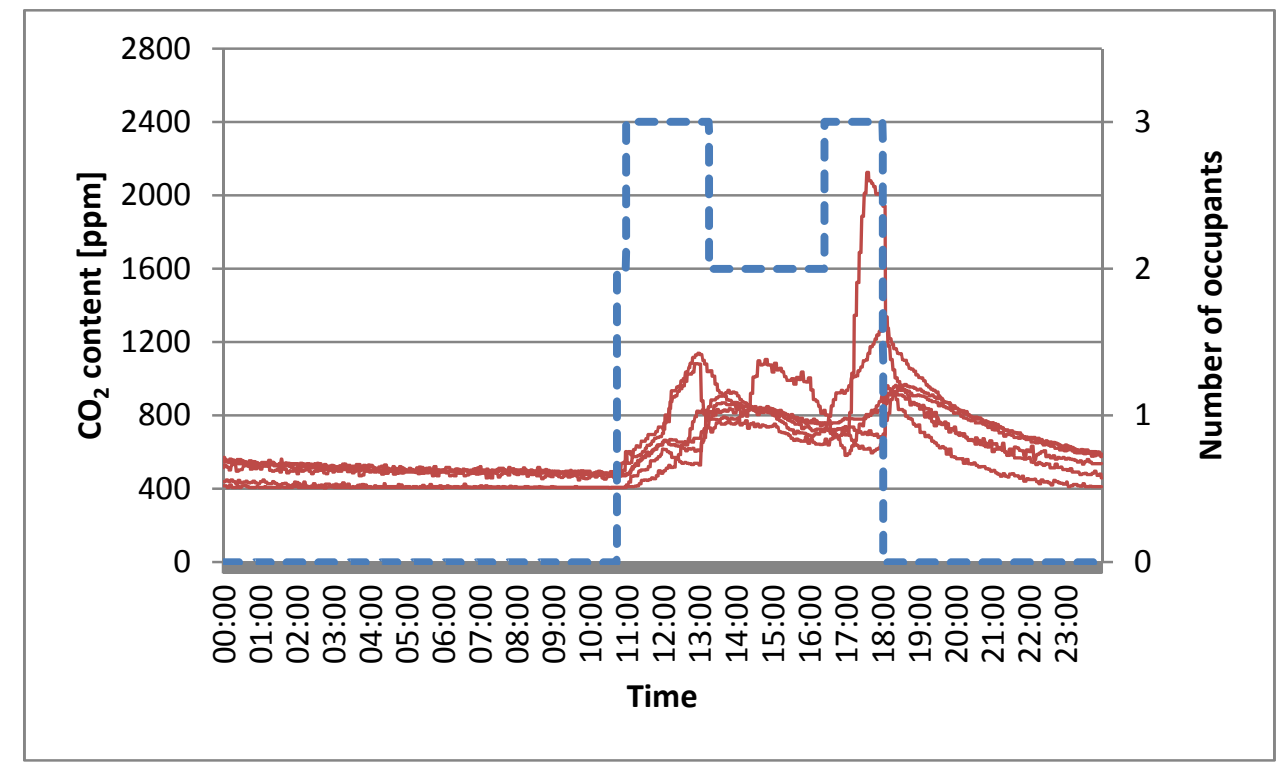

Figure 2: $\mathrm{CO}_{2}$ content in all rooms versus overall human presence

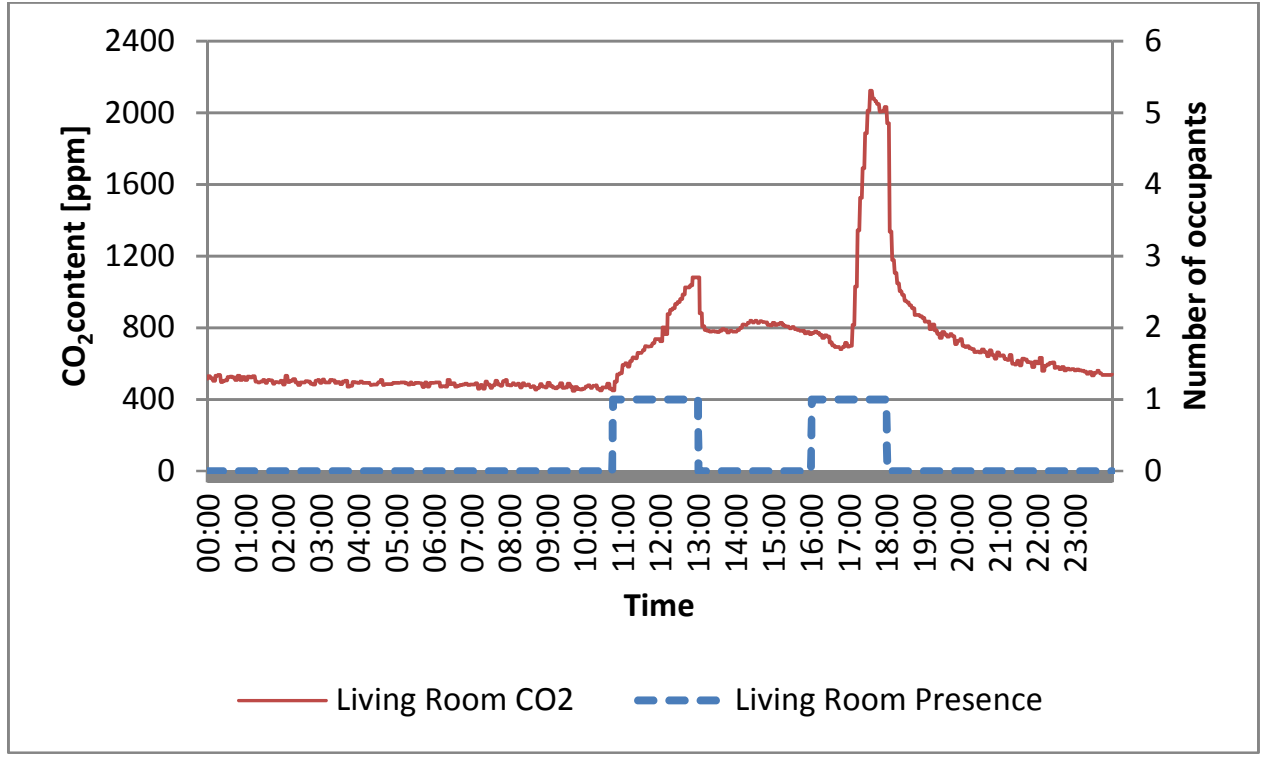

Figure 3: $\mathrm{CO}_{2}$ content versus human presence in the living room 


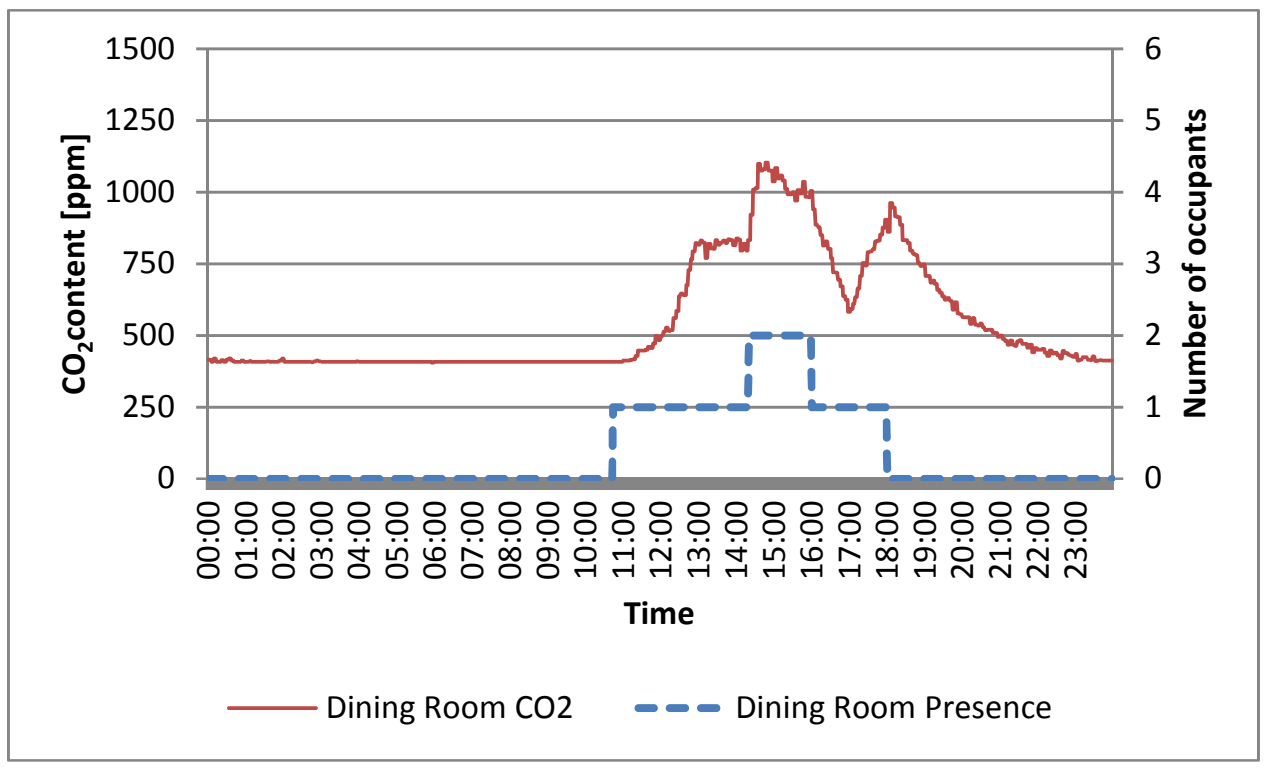

Figure 4: $\mathrm{CO}_{2}$ content versus human presence in the dining room

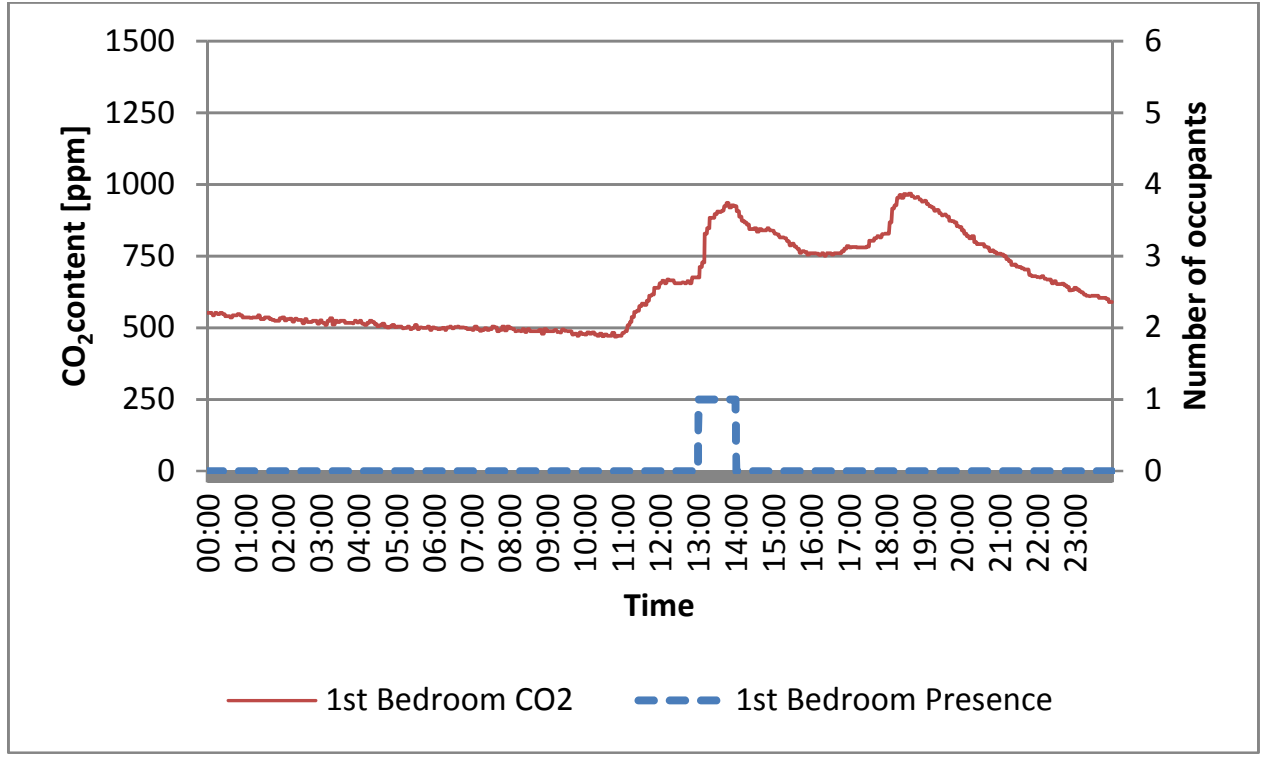

Figure 5: $\mathrm{CO}_{2}$ content versus human presence in the $1^{\text {st }}$ bedroom 


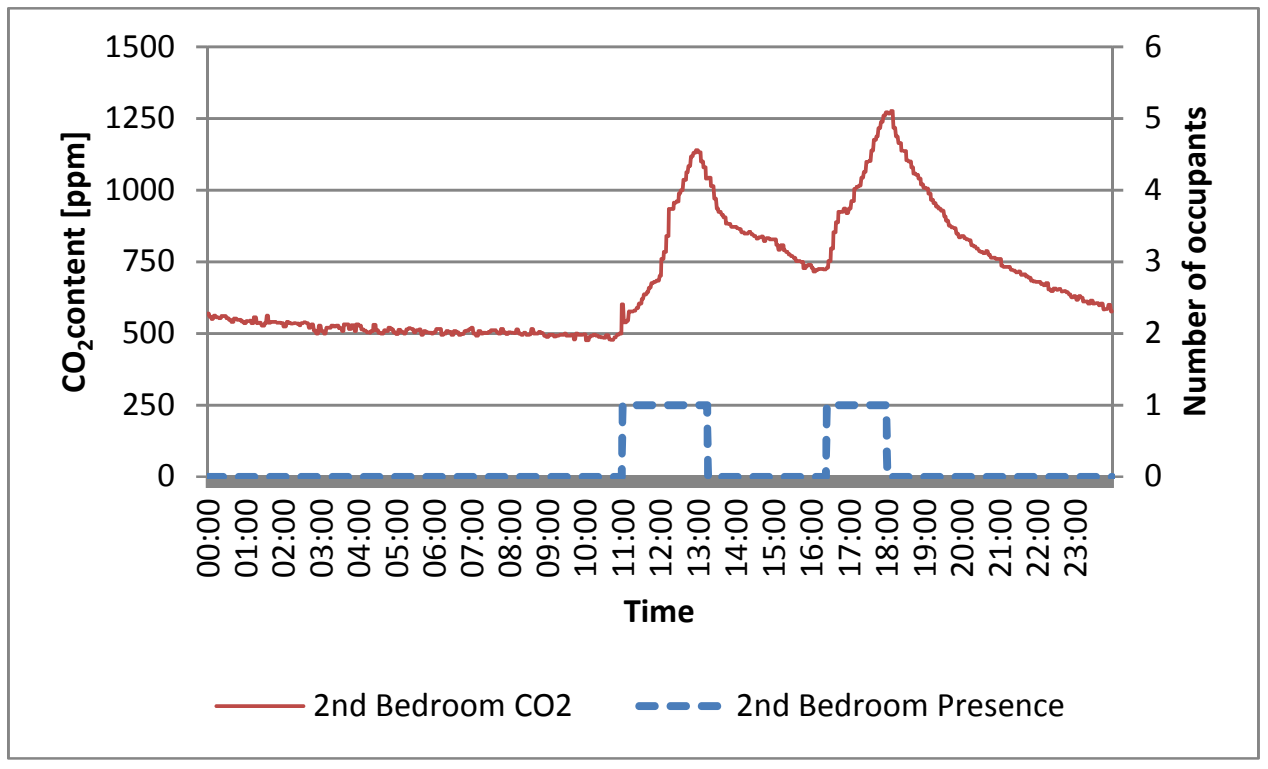

Figure 6: $\mathrm{CO}_{2}$ content versus human presence in the $2^{\text {nd }}$ bedroom

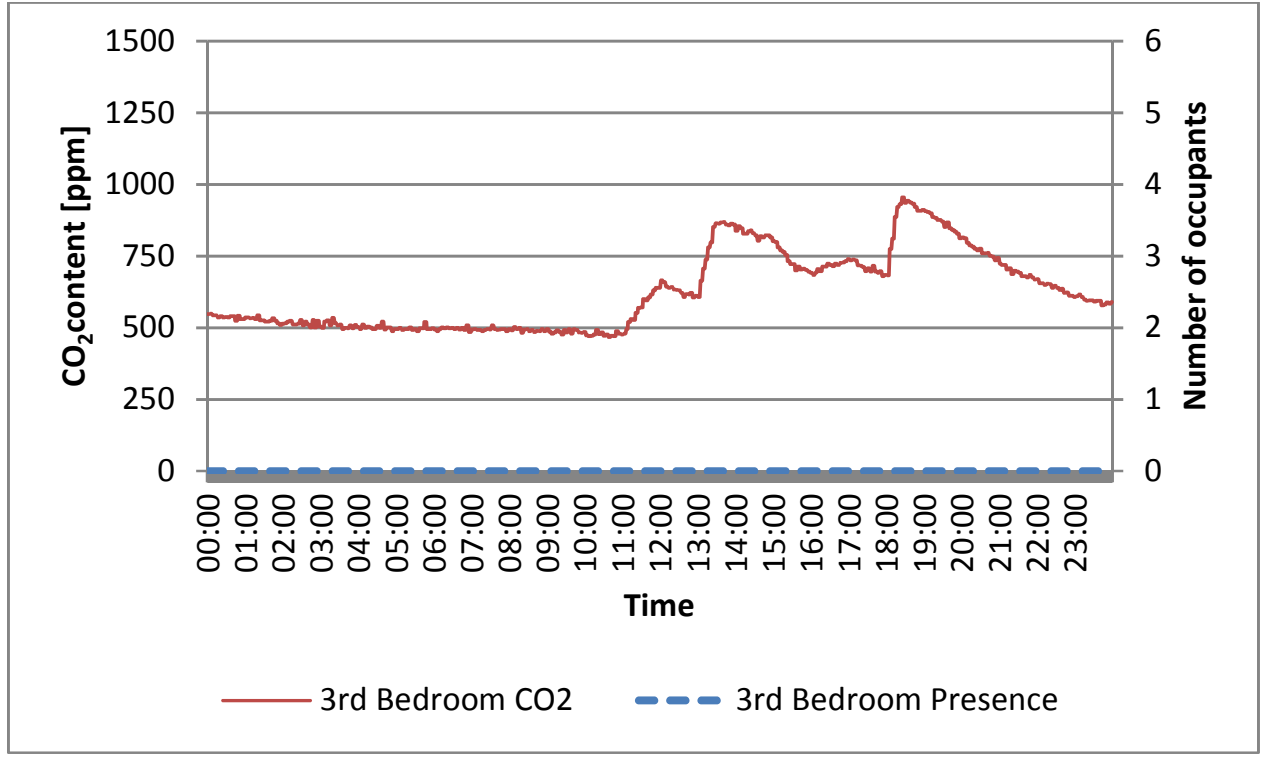

Figure 7: $\mathrm{CO}_{2}$ content versus human presence in the $3^{\text {rd }}$ bedroom 


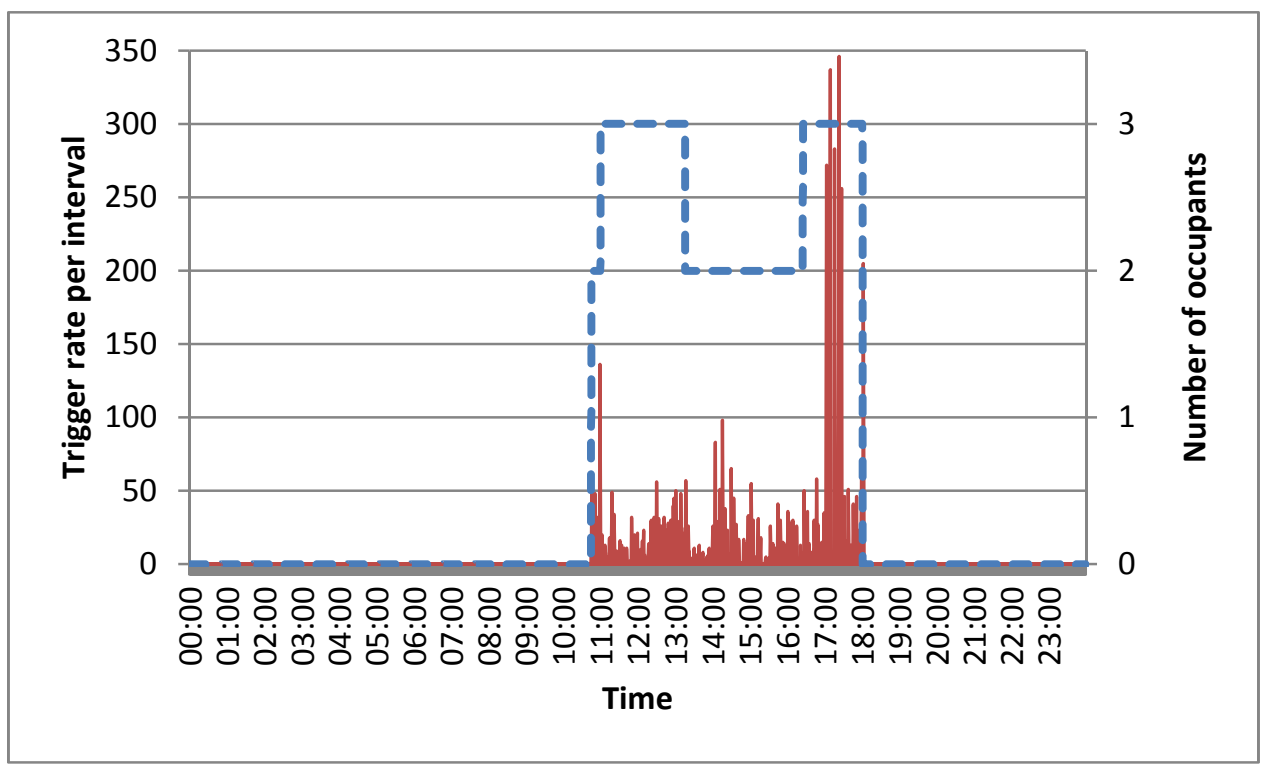

Figure 8: PIR measurements in all rooms versus overall human presence

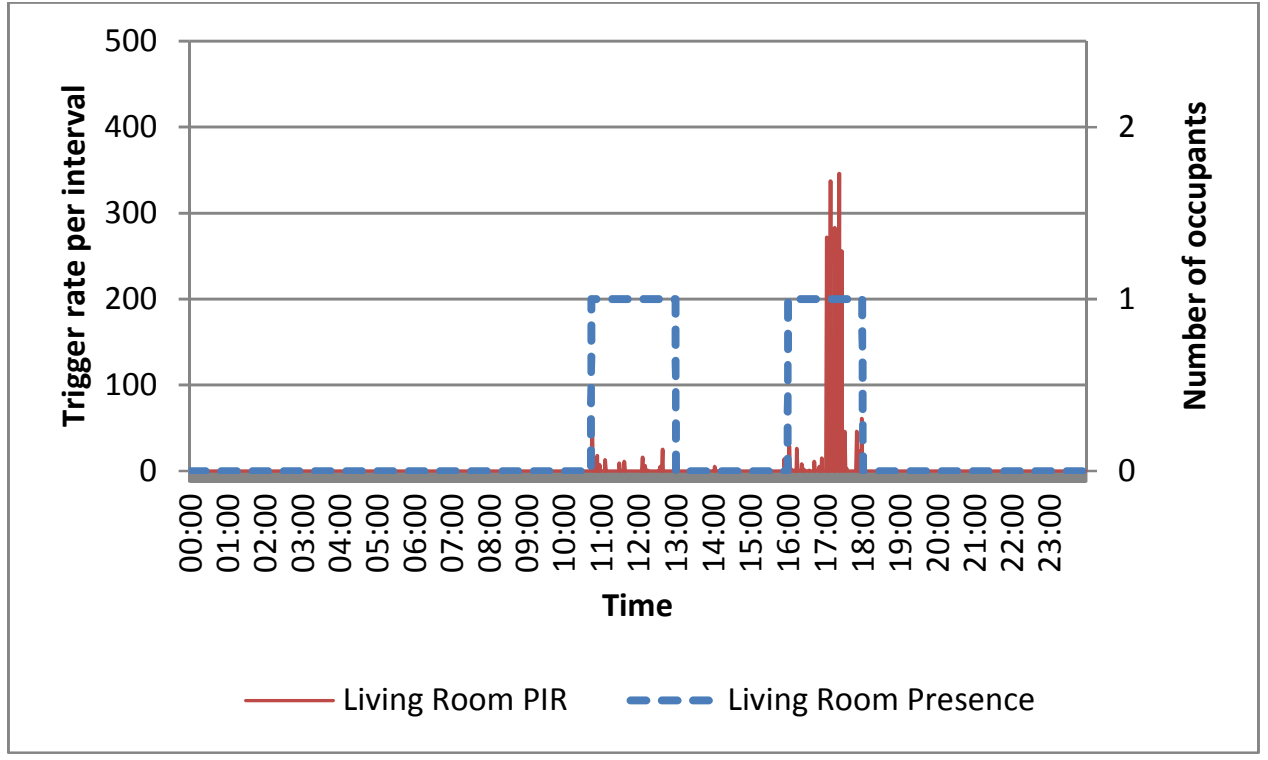

Figure 9: PIR values versus human presence in the living room 


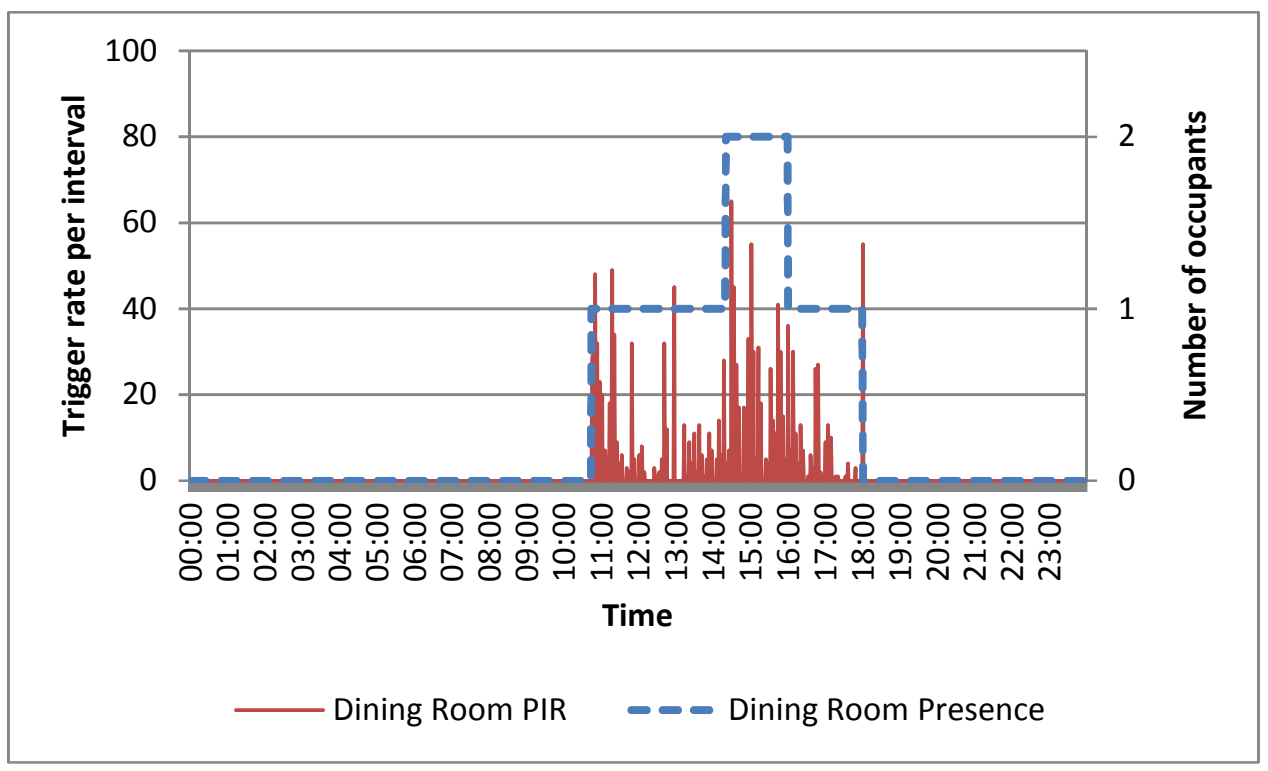

Figure 10: PIR values versus human presence in the dining room

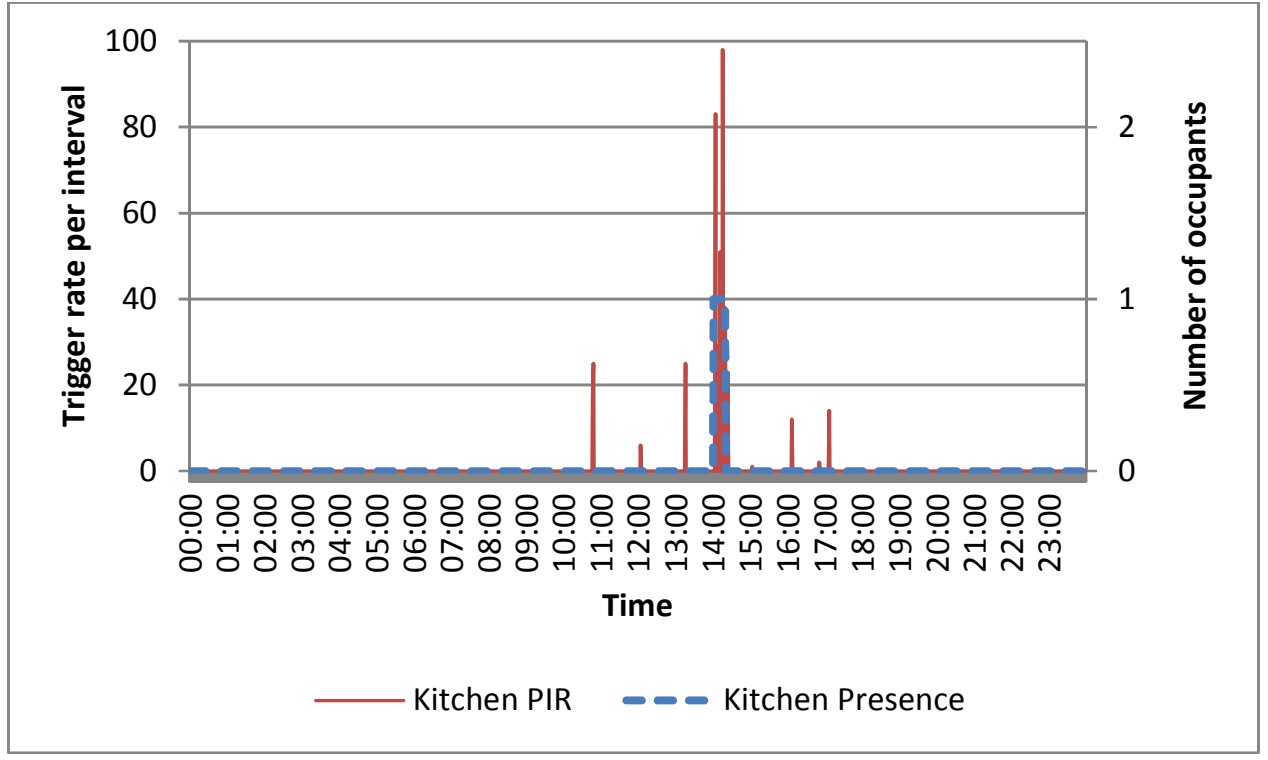

Figure 11: PIR values versus human presence in the kitchen 


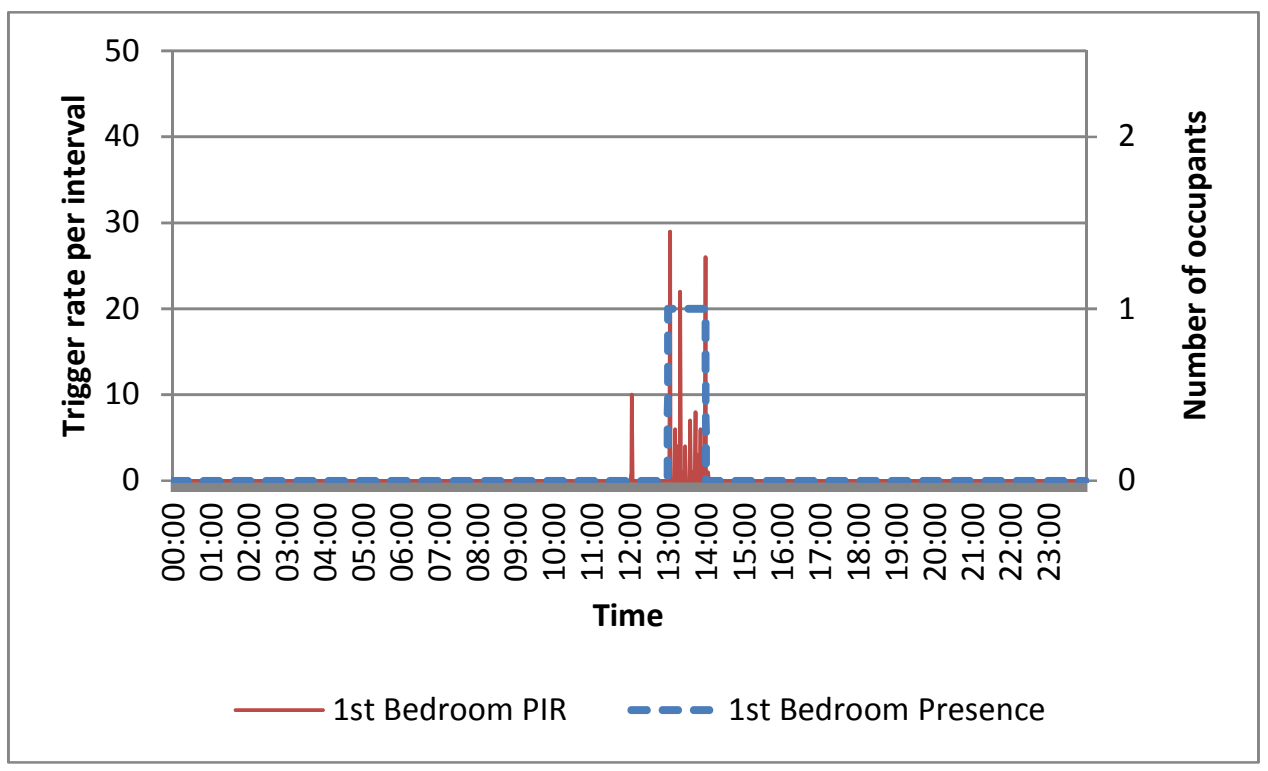

Figure 12: PIR values versus human presence in the $1^{\text {st }}$ bedroom

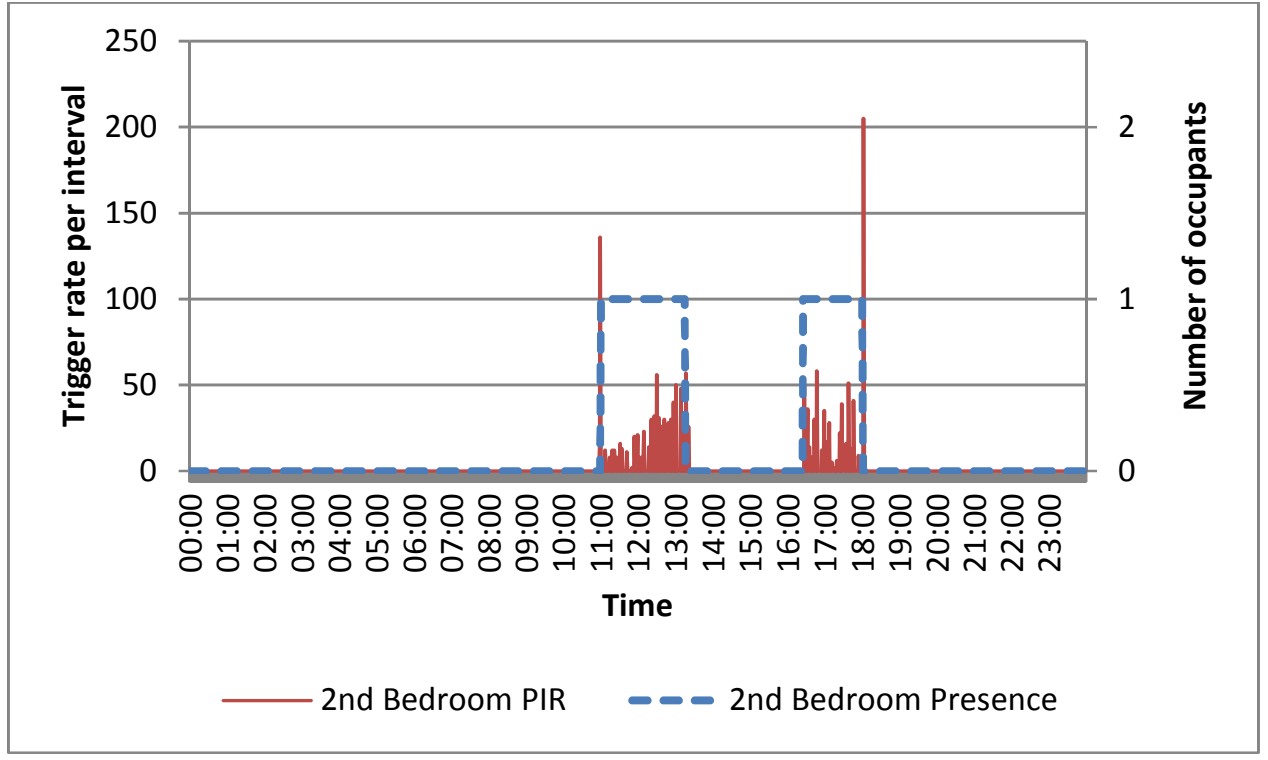

Figure 13: PIR values versus human presence in the $2^{\text {nd }}$ bedroom 


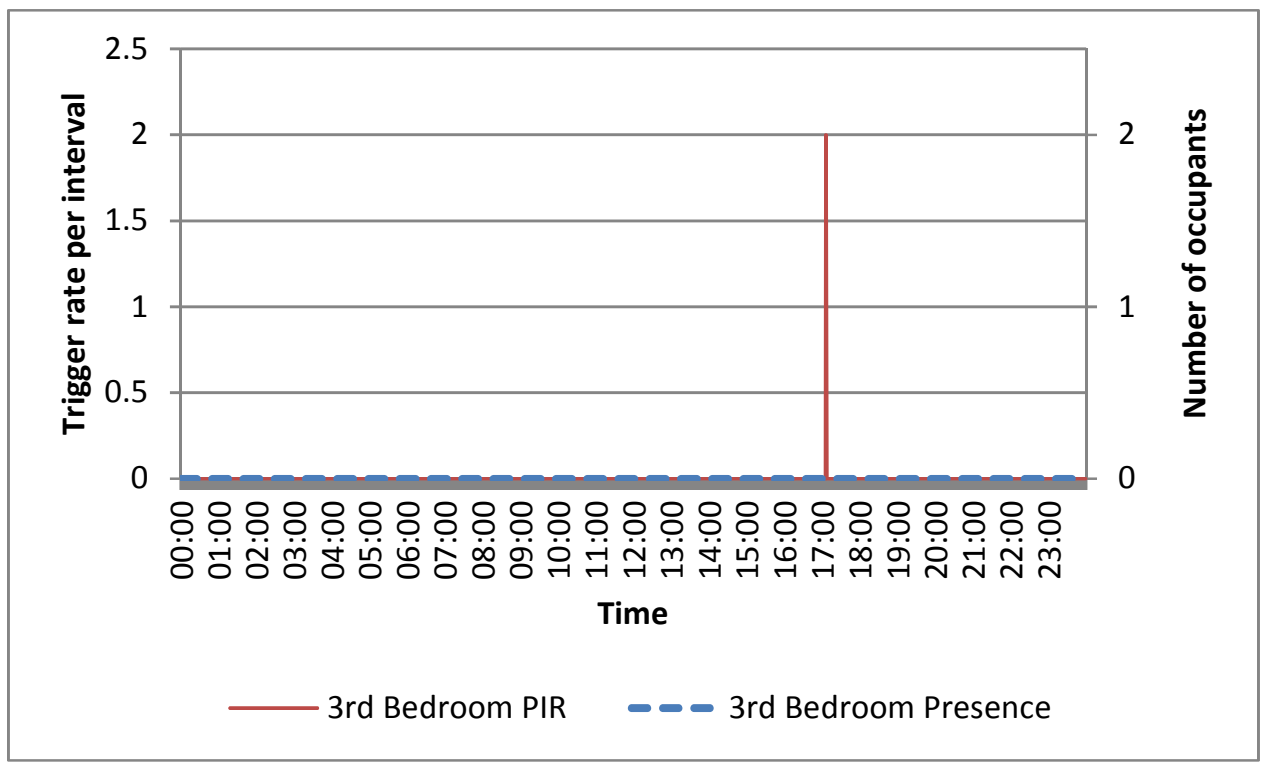

Figure 14: PIR values versus human presence in the $3^{\text {rd }}$ bedroom

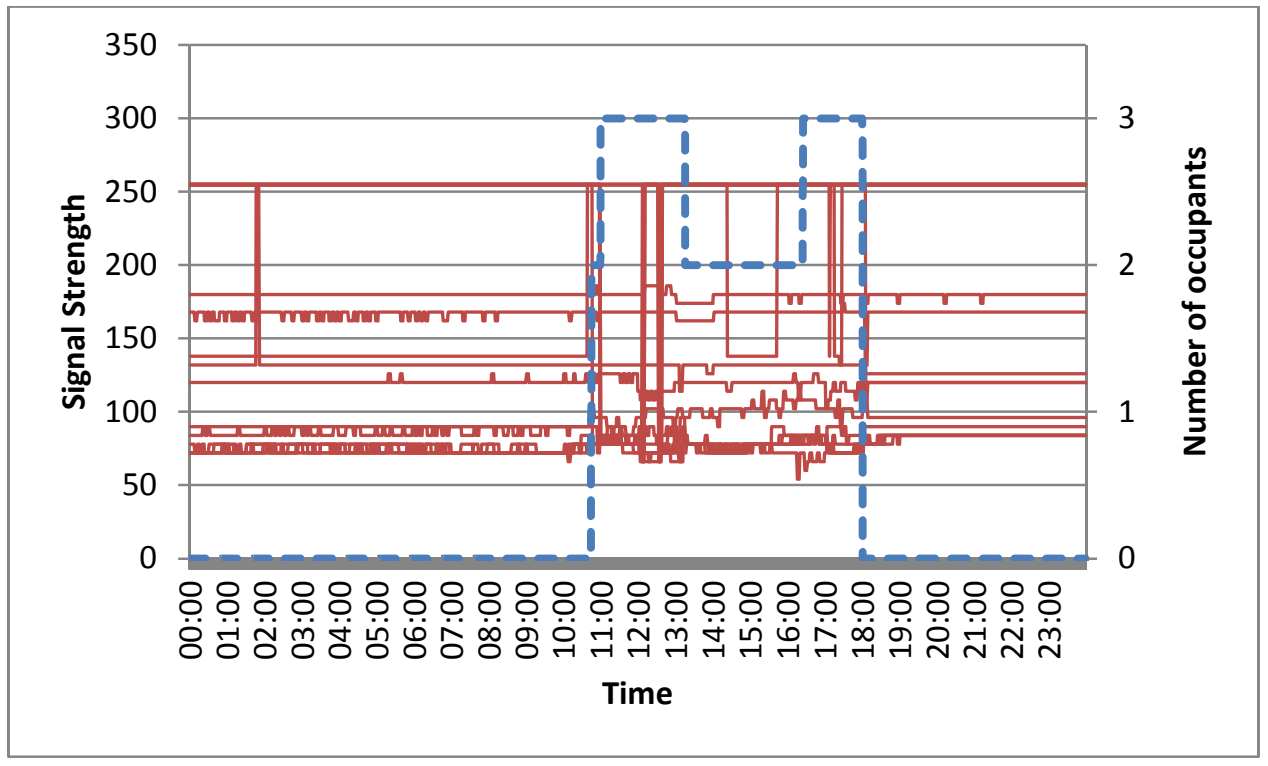

Figure 15: LQI measurements of all the JenNet equipment versus overall human presence 


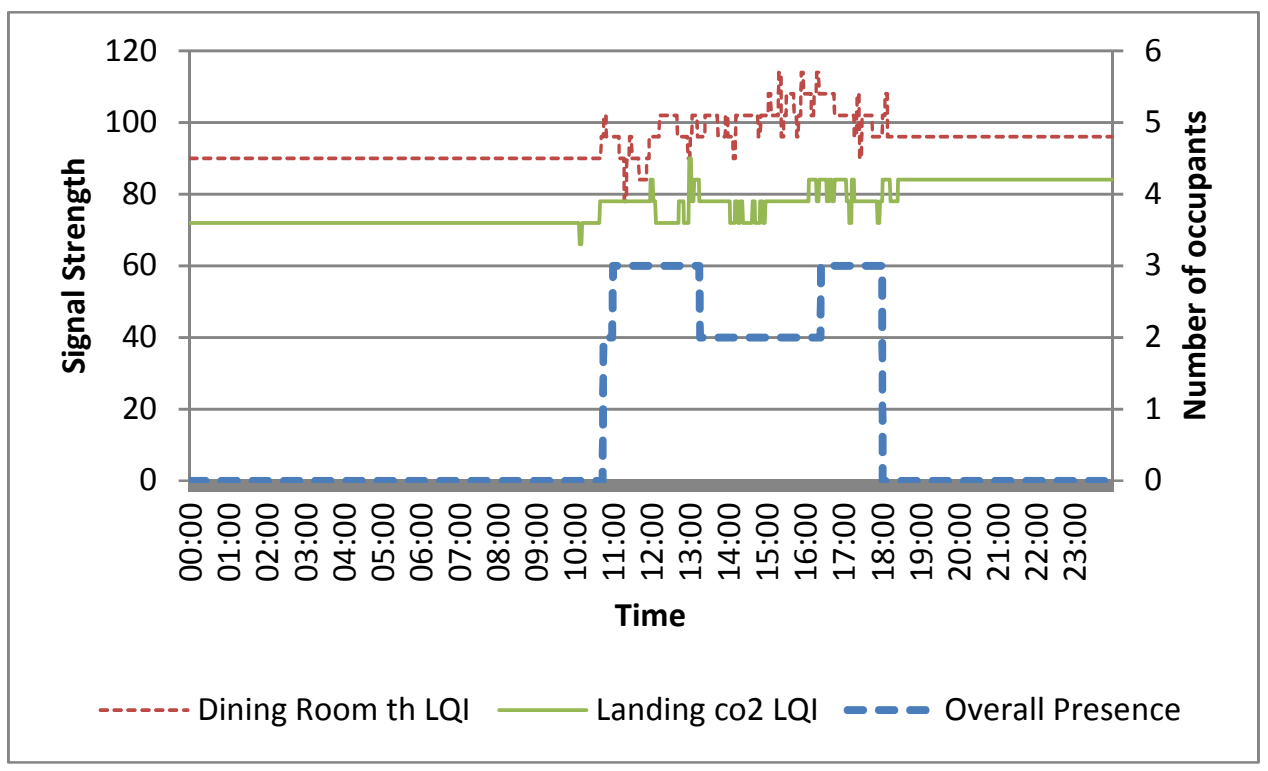

Figure 16: The LQI of two particular sensors versus overall human presence 


\begin{tabular}{|c|c|c|}
\hline & Type of activity & G (L/min per person) \\
\hline \multicolumn{3}{|l|}{ Very light work: } \\
\hline & Seated, writing & 0.27 \\
\hline & Seated, typing & 0.29 \\
\hline & Seated, talking & 0.29 \\
\hline & Seated, filing & 0.31 \\
\hline & Standing, talking & 0.31 \\
\hline & Standing, filing & 0.35 \\
\hline \multicolumn{3}{|l|}{ Light work: } \\
\hline & Walking & 0.44 \\
\hline & Lifting, packing & 0.53 \\
\hline
\end{tabular}

Table 1: Types of human activity associated with different $\mathrm{CO}_{2}$ generation rates (Source: Leephakpreeda et al. $2001[5])$

\begin{tabular}{|llll|}
\hline & Floor Area $\left.\mathbf{( m}^{\mathbf{2}}\right)$ & Average Height $(\mathbf{m})$ & Volume $\left.\mathbf{( m}^{\mathbf{3}}\right)$ \\
\hline Living Room & 16.86 & 2.35 & 39.63 \\
Dining Room & 14.71 & 2.35 & 34.57 \\
Kitchen & 6.84 & 2.35 & 16.08 \\
1st Bedroom & 16.86 & 2.3 & 38.78 \\
2nd Bedroom & 14.71 & 2.3 & 33.83 \\
3rd Bedroom & 6.76 & 2.3 & 15.55 \\
\hline
\end{tabular}

Table 2: Dimensions of the main rooms 


\begin{tabular}{|c|c|c|c|}
\hline & Occupied rooms & Occupant & Adding circumstances \\
\hline $10: 45-11: 00$ & $\begin{array}{l}\text { Living Room } \\
\text { Dining Room }\end{array}$ & A & \\
\hline $11: 00-12: 00$ & $\begin{array}{l}\text { Living Room } \\
\text { Dining Room } \\
\text { 2nd Bedroom }\end{array}$ & $\begin{array}{l}\mathrm{A} \\
\mathrm{B} \\
\mathrm{C}\end{array}$ & \\
\hline $12: 00-13: 00$ & $\begin{array}{l}\text { Living Room } \\
\text { Dining Room } \\
\text { 2nd Bedroom }\end{array}$ & $\begin{array}{l}\mathrm{A} \\
\mathrm{B} \\
\mathrm{C}\end{array}$ & All interior doors were closed \\
\hline $13: 00-14: 00$ & $\begin{array}{l}\text { Dining Room } \\
\text { 1st Bedroom } \\
\text { 2nd Bedroom }\end{array}$ & $\begin{array}{l}\text { B } \\
\text { A } \\
\text { C (until 13:15) } \rightarrow 0\end{array}$ & \\
\hline $14: 00-15: 00$ & $\begin{array}{l}\text { Dining Room } \\
\text { Kitchen }\end{array}$ & $\begin{array}{l}\mathrm{B}(\text { until } 14: 20) \rightarrow \mathrm{A}+\mathrm{B} \\
\mathrm{A}(\text { until } 14: 20) \rightarrow 0\end{array}$ & Cooking food \\
\hline $15: 00-16: 00$ & Dining Room & $\mathrm{A}+\mathrm{B}$ & MVHR on \\
\hline $16: 00-17: 00$ & $\begin{array}{l}\text { Living Room } \\
\text { Dining Room } \\
\text { 2nd Bedroom }\end{array}$ & $\begin{array}{l}\text { A } \\
\text { B } \\
0(\text { until 16:25) } \rightarrow \text { C }\end{array}$ & Window in Living Room was opened \\
\hline $17: 00-18: 00$ & $\begin{array}{l}\text { Living Room } \\
\text { Dining Room } \\
\text { 2nd Bedroom }\end{array}$ & $\begin{array}{l}\text { A } \\
\text { B } \\
\text { C }\end{array}$ & $\begin{array}{l}\text { Occupant A exercised until 17:30 } \\
\text { All interior doors were closed }\end{array}$ \\
\hline
\end{tabular}

Table 3: Timeline of actual room occupation extra from Ubisense system and added circumstances 